\title{
Sediment-Associated Radiocesium Originated from Fukushima Daiichi Nuclear Power Plant Flowing from Ohori River to Lake Teganuma
}

\author{
Yukio KOIBUCHI ${ }^{1)}$, Michio MURAKAMI ${ }^{2}$, Keisuke SUEKI ${ }^{3)}$, Yuichi ONDA ${ }^{4)}$ \\ 1) Graduate School of Frontier Sciences, The University of Tokyo, 5-1-5 Kashiwanoha, \\ Kashiwa, Chiba 277-8563, Japan \\ 2) Institute of Industrial Science, The University of Tokyo, 4-6-1 Komaba, Meguro, Tokyo \\ 153-8505, Japan \\ 3) Center for Research in Isotopes and Environmental Dynamics, University of Tsukuba, 1-1-1 \\ Tennodai, Tsukuba, Ibaraki 305-8572, Japan \\ 4) Department of Integrative Environmental Sciences, University of Tsukuba, 1-1-1 Tennodai, \\ Tsukuba, Ibaraki 305-8502, Japan
}

\begin{abstract}
Radiocesium has been deposited after the Fukushima Daiichi Nuclear Power Plant (FDNPP) accident and affix to the soils inland. The soils flowed into Lake Teganuma through Ohori River. Field observation was carried out to quantify radiocesium, associated with sediments, transported around Lake Teganuma and Ohori River from October 2011 to March 2014. We quantified the sediment transported to Ohori River and found that the total radiocesium stock in Ohori River was $2,190 \mathrm{MBq}$ which was mostly attached to the fine-grained sediment of silt in 2012. The radiocesium, transported as a suspended sediment in the Ohori River watershed, was approximately 10 percent of the total fallout of $2 \mathrm{TBq}$. The total flux of radiocesium in Ohori River were 3,800 MBq in 2012 and reduced to $6.65 \mathrm{MBq}$ in 2013 . These results denote that most of the radiocesium-polluted sediments were transported downstream in 2011 and sharply decreased after 2012. When a similar study was conducted in Abukuma River, only $1 \%$ of the total fallout was calculated indicating transport was 10 times that of the Abukuma River. This is attributed to be urbanization of Teganuma basin in comparison to the Abukuma basin, thus more cesium were transported in a shorter time period.
\end{abstract}

Keywords: radiocesium, radiocesium flux, suspended sediment transport

\section{INTRODUCTION}

River-based transport of sediment from land is essential for understanding the fundamentals of the river and lake environments, as the influence on ecosystems of sediment transport through landforms is far-reaching. Not only does the amount of transported sediment change drastically with the weather (sun/rain), transport behavior also depends on grain size and ion concentration. In particular, silts and other fine grains become suspended in rivers, tumble along the riverbed or becoming embedded, ultimately leading to difficulty in quantifying the amount of sediment transported (Reid and Larronne, 1995). Radiocesium, which originated from the FDNPP accident, clings strongly to fine sediment before being transported in the water environment along with sediment and finally accumulating downstream (He and Walling, 1996), there are growing concerns about how this will have an impact on the river and lake ecosystems into which it flows through. However, there is optimism that the strong adsorption characteristics of this radiocesium on fine-grained sediment will enable us to trace the transport of this sediment. The half-life of cesium-137 is approximately 30 years, and only extremely low concentrations were found in Japanese soil prior to 2011. Moreover,

Address correspondence to Yukio Koibuchi, Graduate School of Frontier Sciences, The University of Tokyo, Email: koi@k.u-tokyo.ac.jp

Received May 24, 2014, Accepted December 19, 2014. 
because the half-life of cesium-134 is only 2 years, scarcely amount was found in the ground prior to 2011. Hence, its presence or absence in water enables us to use it as a tracer for distinguishing whether sediment in the water existed prior to, or after, 2011. In addition, because cesium tends to attach to sediment and accumulates at the river mouth at a higher concentration than upstream, cesium can also be used for assessing sediment budget. In particular, the accident at Fukushima derived a wealth of detailed aerial monitoring and municipal surveys that provide quantitative insight into how much cesium was deposited onto the land surface (JAEA, 2011; MEXT, 2011a). With these mean, the sediment budget will be quantitatively evaluated. For instance, by tracing where cesium is, where it travels to, and how much travels, we will be able to elucidate the sediment transportation.

A similar study associated with nuclear atmospheric tests was conducted in 1960, but information at the time was restricted and the measurement devices of the time were few in number and had low degrees of accuracy. In order to understand the 1986 explosion at Chernobyl, intense surveys were carried out in Ukraine, Russia, and around Europe (IAEA, 2006; Golosov et al., 2012). The results were compiled into Smith and Nicholas (2005). However, the sites of this accident in the South Urals and Japan have very different climates and rainfall patterns. The area near Chernobyl experiences rainfall of approximately $300 \mathrm{~mm} /$ year and has a cool humid climate. Japan, however, is exposed to nearly 6 times as much rainfall at roughly $1,700 \mathrm{~mm} /$ year and has a monsoon climate with different soil and forests (Yasunari et al., 2011). For these reasons, it is thought that the effect of downward flow is bigger in Japan, causing difficulty in using the results of studies based on Chernobyl to predict the transportation of radiocesium that originated from the FDNPP.

In Japan, the accident led to vigorous research conducted in Fukushima Prefecture, which experienced a high-dose of radiation (Chino et al., 2011; Morino et al., 2011; Hirose, 2012). In the notably contaminated Abukuma water system, the amount of radiocesium and the sediment have been quantified (Yamashiki et al., 2014), but the numerous woodlands in Fukushima Prefecture and wealth of dairy and farming makes it difficult to simply apply these results to urban areas. In particular, due to the asphalt roads and commercial facilities that cover much of the soil in urban areas, and the tendency to build large houses on the small amount of land even in residential area, it is predicted that the amount of transported radiocesium will differ here from Fukushima Prefecture as a whole. A comparison of both sides is not only effective for grasping the behavior of radiocesium in urban areas, but also for understanding differences in sediment transport. In addition, it is also thought that the sewer systems in urban areas contribute to speeding up the release of these materials into rivers and the ocean following rainfall. Until now, there has been insufficient investigation into areas of relatively high population density for both accidents.

Lake Teganuma and Ohori River, the areas chosen for this study, are located in the relatively densely populated suburbs of Kashiwa, Nagareyama, and Abiko in Chiba Prefecture (Kimura and Koibuchi, 2010). These areas have been labeled hot spots since the accident. They are known as areas where radiocesium was deposited in large amounts compared to their surroundings, and because they receive a large dose of air coming from a part of Fukushima. Hence, Japanese Government has chosen Lake 
Teganuma and Ohori River as areas subject to decontamination. Inland water fishing had taken place at Lake Teganuma until the FDNPP accident. The presence of radiocesium not only affect the surrounding ecosystem, but also has an extremely important effect on society as well.

Nihei et al. (2013) evaluated radiocesium stocks in Lake Teganuma and radiocesium fluxes in Ohori River in June and July 2012. Since we have conducted field observation since October 2011 to 2013, our result in 2012 was compared to the Nihei's estimation in 2012. Our recent data obtained after 2013 was also compared to the Nihei's data in 2012.

Therefore, we conducted field observations both at Lake Teganuma and its largest tributary, Ohori River to clarify where and how much radiocesium was distributed. We then grasped how this changes over time for understanding temporal transport fluxes. This research aims to provide pertinent information for predicting future behavior of radiocesium.

\section{MATERIALS AND METHODS \\ Sampling site}

Figure 1 shows the study area, i.e., Lake Teganuma and Ohori River, which is ca. 200 $\mathrm{km}$ from the FDNPP and is surrounded by densely populated urban areas including Nagareyama City and Kashiwa City in Chiba Prefecture. After the accident, radiocesium fell mainly with rain. Radiocesium adhered to the road dust, and the fine-grained sediment was transported to Ohori River through precipitation events. This area, which is far from Fukushima, was chosen for the following reasons. First, at Fukushima, it was not possible to distinguish between the radiocesium directly supplied by air and those arriving at the monitoring sites by sediment movement. Second, as $71 \%$ of Fukushima is forest, the radiocesium attached to the fine-grained sediment was unlikely to travel (Kato et al., 2012). Third, a lot of observations were already carried out in Fukushima Prefecture (Nagao et al., 2013). On the other hand, the urban areas of these cities are paved with asphalt, maybe speeding up the transportation of radiocesium. Also, since the fallout of radiocesium in this area was not small, the cause of the increase in radiocesium concentrations is attributed to the transportation of fine-grained sediments. Also, compared to the Fukushima coastline, which is open to the Pacific Ocean, Lake Teganuma is not affected by ocean currents and waves; thus, making it easier to track the sediment transportation process.

The first round of sampling was conducted in October 2011 and covered three sites along the Ohori River that flows into Lake Teganuma. At Lake Teganuma, field observation was carried out at 3 sites along the lake. At all these locations, samples of water and sediment were collected, and water temperature, salinity, and turbidity were measured using a multi-parameter water quality meter (6600V2, YSI Inc., Yellow Springs, USA). After establishing the baseline distribution of radiocesium, sampling was repeated at the same sites: every 1 to 3 month at 10 locations (Fig. 1) from river mouth to $7 \mathrm{~km}$ upstream in Ohori River, and every 3 month at 7 locations in Lake Teganuma (Fig. 1) from April in 2012. As Fig. 1 shows, Ohori River connects to Lake Teganuma at Stn.L1 and lake water flows out to Tone River at Stn.L7. These samples 


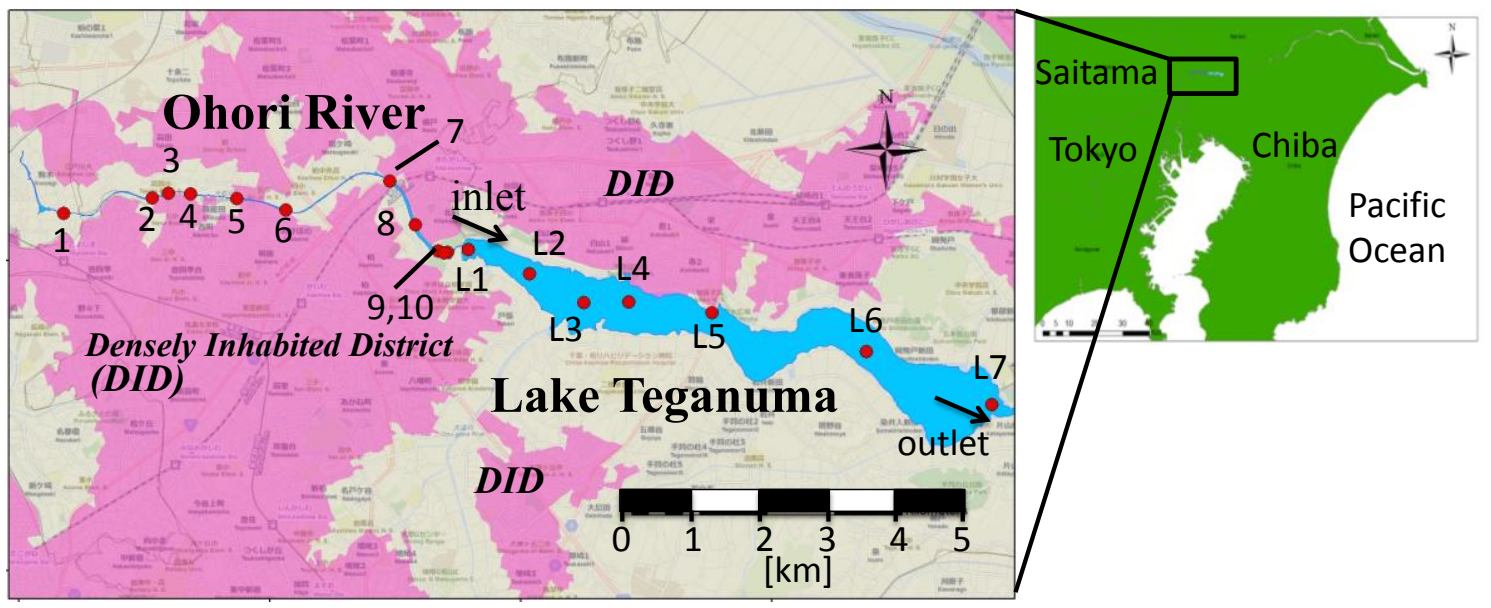

Fig. 1 - Observation sites of Ohori River and Lake Teganuma (left) with Densely Inhabited District (DID), showing the location of the measurement site (right).

were promptly brought to the laboratory and analysed as follows. In the middle of Ohori River at Stn.6 and 7, water level was measured every $10 \mathrm{~min}$ (MLIT, 2014). Meteorological data was used at Abiko observation station (JMA, 2014).

\section{Analytical methods}

The sediments were sampled with piston coring device (DIK-180A, Daiki Rika Kogyo Co., Ltd., Kounosu, Japan). Water samples were collected at Stn.6 every month with wide-mouth Teflon bottles to measure the suspended sediment and its radiocesium concentrations.

The core samples were sliced and fully dried over two hours at $105^{\circ} \mathrm{C}$, and were analysed using gamma-ray spectrometry and a Germanium $(\mathrm{Ge})$ semiconductor detector (GMX, ORTEC Inc., Oak Ridge, USA). The sample was placed in an iron and lead chamber of $15 \mathrm{~cm}$ thickness to reduce the influence of natural radiation. The apparatus was calibrated using the IAEA-444 soil certified reference material. The particle size of the sediments and suspended sediment concentrations were measured using a laser diffraction particle size analyser (SALD-3000s, Shimadzu Inc., Kyoto, Japan). In addition, suspended sediment concentrations of ca. $10 \mathrm{~L}$ were filtered and dried using glass fiber filters (GF/C, pore size, $1.2 \mu \mathrm{m}$; Whatman, Kent, UK), and the radiocesium on the filter was analysed using the germanium semiconductor detector.

\section{Flux calculation methods}

In Ohori River, ultrasonic water level sensor was measured from the bridge at Stn.6 and the water level was measured every 10 minutes (MLIT, 2014). In addition, in situ turbidity sensor was installed at Stn.6 and turbidity was measured every 10 minutes. Turbidity sensor measurements were correlated with suspended sediment concentrations to enable conversion from turbidity [FTU] to suspended sediment concentrations $[\mathrm{mg} / \mathrm{L}]$ using a calibration curve developed through water samples. Figure 2 shows the relationship between turbidity and suspended sediment concentrations. Most of the 


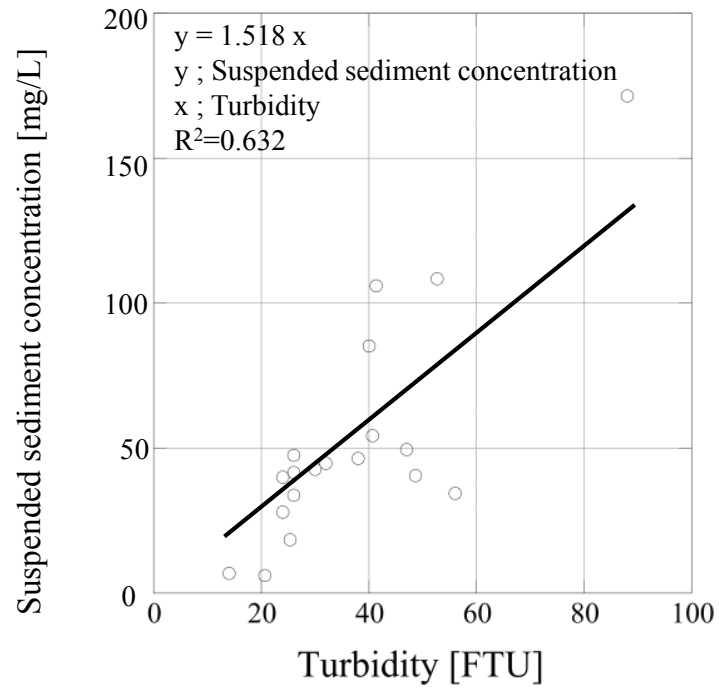

Fig. 2 - Conversion from Turbidity [FTU] to Suspended sediment concentration $[\mathrm{mg} / \mathrm{L}]$.

samples were around the average suspended sediment concentrations of $50 \mathrm{mg} / \mathrm{L}$, and a few suspended sediment concentrations were greater than $50 \mathrm{mg} / \mathrm{L}$. Although only limited data was available at concentrations greater than $50 \mathrm{mg} / \mathrm{L}$, a linear relationship between turbidity and suspended sediment concentrations $\left(\mathrm{R}^{2}=0.632\right)$ was observed. The suspended sediment flux was calculated based on this linear relationship. Using cross-sectional surveys and measured flow velocities (River Surveyor M9, SonTek, San Diego, USA), water levels were converted to discharge at Stn.6. Multiplication of suspended sediment concentration and flow enabled the calculation of suspended sediment flux [ton/hour] and cesium flux [Bq/hour].

\section{Stock calculation methods in Ohori River and Lake Teganuma}

The radiocesium stock in Ohori River and Lake Taganuma were estimated as follows:

$$
Y_{\mathrm{Cs}, \mathrm{stock}}=\Sigma\left\{\Sigma\left(D \cdot \rho_{d} \cdot X_{C S}\right) L \cdot w\right\}
$$

where $Y_{\mathrm{Cs} \text {,stock }}[\mathrm{Bq}]$ is the estimated total stock of radiocesium, $L[\mathrm{~m}]$ is the distance between sampling sites, $w[\mathrm{~m}]$ is the width of river or lake, $D[\mathrm{~m}]$ is the depth of radiocesium contaminated sediment in each layer, $\rho_{d}\left[\mathrm{ton} / \mathrm{m}^{3}\right]$ is the density of the sediment (i.e., $1.53 \mathrm{ton} / \mathrm{m}^{3}$ ), and $X_{C s}[\mathrm{~Bq} /$ ton] is the measured concentration of radiocesium. To calculate the radiocesium stock of each site, the calculated radiocesium stock of each layer over the contaminated sediment was integrated. The total stock of radiocesium is estimated by integration of the radiocesium stock of all observation sites.

\section{RESULTS AND DISCUSSION Background condition}

Measurements taken at the study areas over a period of 3 years determined an average rainfall of $115 \mathrm{~mm} / \mathrm{month}$, nearly double the global average of $77 \mathrm{~mm} / \mathrm{month}$. During 
the rainy season from May to June, the average increased to $161 \mathrm{~mm} / \mathrm{month}$. Although the average for the summer months of July and August fell to only $82 \mathrm{~mm} / \mathrm{month}$, it quickly increased again to $212 \mathrm{~mm} / \mathrm{month}$ from October through November due to the effect of typhoons. From December to March, the average fell once again to 70 $\mathrm{mm} / \mathrm{month}$, but nevertheless came close to the global rainfall average. In addition, the precipitous mountains in Japan's Chubu region create rivers with steep gradients in the area. This causes the flow rates of the connecting rivers to rapidly increase when it rains, and this in turn tends to increase the transport of sediment. As a result, there is a tendency towards easier travel of the sediment contaminated with radiocesium that had fallen on the land surface.

Furthermore, the opening of a new railway in the study area in 2005, which enabled convenient travel to the center of Tokyo in about 30 minutes, spurred on development of these suburbs and a subsequent increase in population. As seen in Fig. 1, a large portion of the western side of the Lake Teganuma watershed has a population density of 5,000 persons $/ \mathrm{km}^{2}$.

Lake Teganuma, which is fed by the Ohori River, is shallow (average depth of $0.9 \mathrm{~m}$ ) and has had land reclamation work done to the lake that already roughly $80 \%$ has been filled. Because of this landfilling, it has been divided into north and south sections whereby the northern part is called upper-lake (uenuma), and the southern part lower-lake (shitanuma). This study concerns only the area of upper-lake, which makes up $95 \%$ of Lake Teganuma. 480,000 people live in the $148.85 \mathrm{~km}^{2}$ watershed. Because the average depth of the lake is $0.9 \mathrm{~m}$, strong winds can cause mixing of the water body. This draws sediment from the lakebed that has been accumulating in the lake and causes high turbidity while simultaneously decreasing transparency. The deepest part of the lake is $3.8 \mathrm{~m}$, but areas of this depth are limited only to a portion of the river mouth. Fish catch of common carp and crucian carp were approximately $200 \mathrm{t} / \mathrm{year}$, but fishing has been restricted since the accident at the FDNPP. According to a statement a year after the accident on Mar. 12, 2012, topmouth gudgeon (motsugo) and suji-ebi caught in Lake Teganuma on Mar. 3, 2012 had levels of radiocesium at $171 \mathrm{~Bq} / \mathrm{kg}$ and $91 \mathrm{~Bq} / \mathrm{kg}$, respectively (Division of Agriculture, Forestry and Fisheries of Chiba Prefecture, 2012). For this reason, as of September 2014 until present, fishing is prohibited, not only causing unease for the surrounding residents, but also impacting the lives of fishermen.

\section{Distribution of radiocesium}

Figure 3 shows the temporal variation of cesium in surface layer of the sediment (the sum of ${ }^{134} \mathrm{Cs}$ and ${ }^{137} \mathrm{Cs}$ of surface $1-\mathrm{cm}$ thickness) in Ohori River. The change of radiocesium concentration was always short term in all places except Stn.4. For example, at upstream Stn.2, the concentration was high in 2011 and then decreased greatly, increased rapidly again in March 2013, and suddenly decreased afterwards. A similar trend was also seen in Stn.6, but the extent of the change was smaller in Stn.6, where the peak concentration was lower, than in Stn.2. On the other hand, it was only at Stn.9 that peak appeared in September 2012. This is probably because the sediment accumulation area containing radiocesium changes with time depending on the amount of rainfall. In addition, except in Stn.9, the peak appeared in March 2013 where the concentration was higher than in October 2011. This indicates that the most recent rainfall is a key factor because the transportation of sediments contaminated with 
radiocesium is short term; for example, due to downstream effects, the peak sediment concentration created by the typhoon in August 2011 went down shortly after. However, the cause of such temporal variations cannot be determined only from the change in the amount of surface layer sediments alone. Therefore, core sampling results were examined to understand the radiocesium in the sediment.

Figure 4 shows time series of the vertical distribution of radiocesium in the sediment of Ohori River. Here, the results of monthly measurements from July to December 2012 in Ohori River are shown to discuss the concentration variations in more detail. At upstream Stations 1 and 2, the concentration was low in whole, and radiocesium was distributed within $10 \mathrm{~cm}$ from the sediment surface, almost uniformly over the depth. At midstream Stations 4 and 5, radiocesium was distributed within $15 \mathrm{~cm}$ from the sediment surface, not uniformly over the depth. In addition, the overall concentration changed, low in September and increasing afterwards, while the distribution profile was unchanged. Furthermore, the concentration was in between the upstream and downstream values. Also in the downstream area, the peak depth in the vertical distribution remained constant over time. At Stn.9, the thickness of the layer containing radiocesium increased from $20 \mathrm{~cm}$ to $30 \mathrm{~cm}$, showing the deposition of additional sediments contaminated with radiocesium. Among the downstream areas, the change was smallest at Stn.11, but the sedimentation depth was smaller only by $2 \mathrm{~cm}$ apparently because the outer layer was scraped. In addition, the average concentration, about $8,000 \mathrm{~Bq} / \mathrm{kg}$, was higher here than in the upstream and midstream areas. As Figs. 3 and 4 show, the transportation of the sediment containing radiocesium takes place within a short period of time in Ohori River. In addition, while the concentration changes, the vertical profile does not greatly change; this indicates that, at the time of the rain, large-sized ingredients such as sand tend to stay where they are while small-sized ingredients such as silt are transported downstream, repeatedly deposited and scraped within a short period of time. Accordingly, the change is slower and the concentration is higher in the down stream area than in the upstream and midstream areas. Silt was found accumulated most abundantly in down stream areas; this is evidence supporting that the layer thickness and concentration vary depending on the supply and transportation of fine sediments.

Similarly, Fig. 5 shows the vertical distribution of radiocesium in the Lake Teganuma into which Ohori River flows. This figure shows that the concentration was high at the mouth of the river in 2012 (Stn.L1), and the same trend was seen in March 2013. In December 2013, the concentration at the mouth of the river showed a decrease, while the concentration increased at the outlet of Lake Teganuma (Stn.L7). This indicates that radiocesium flowed through the Lake Teganuma. In addition, part of radiocesium flowed out of Lake Teganuma into Tone River. 


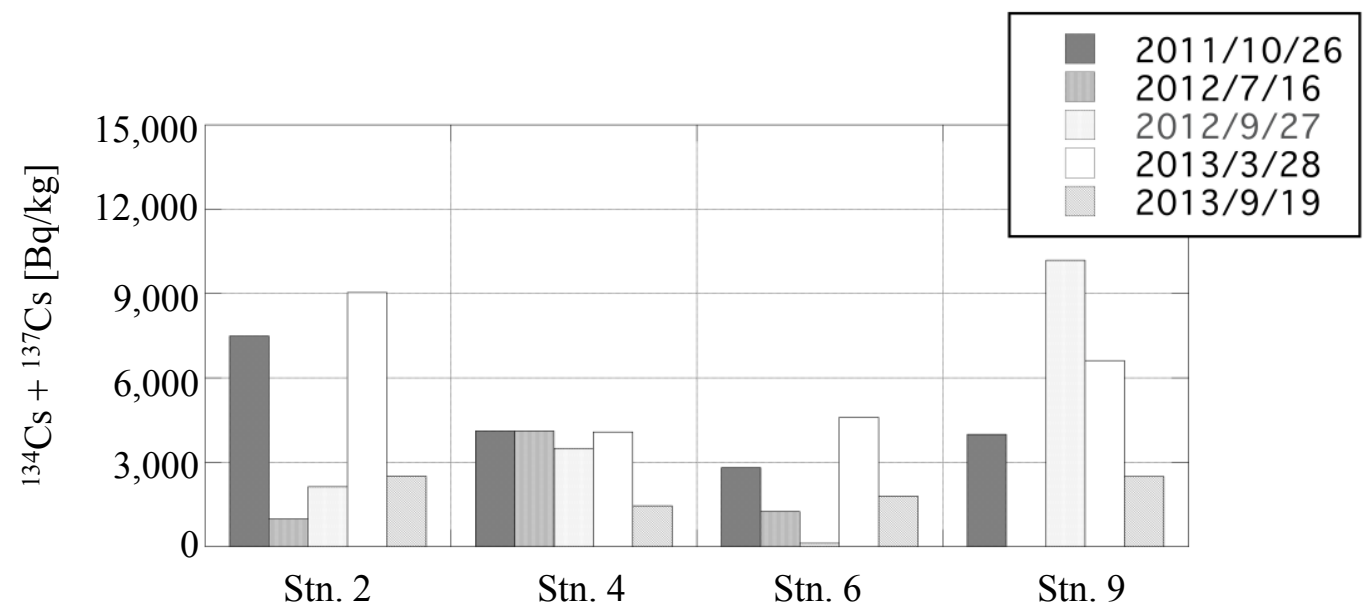

Fig. 3 - Time series of radiocesium concentration at different stations in Ohori River.

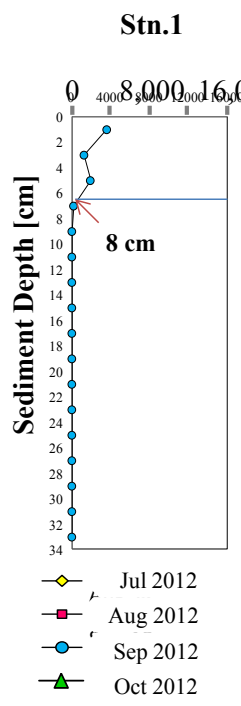

Stn.2

Stn.4

Stn.5

Stn.9

Stn.11
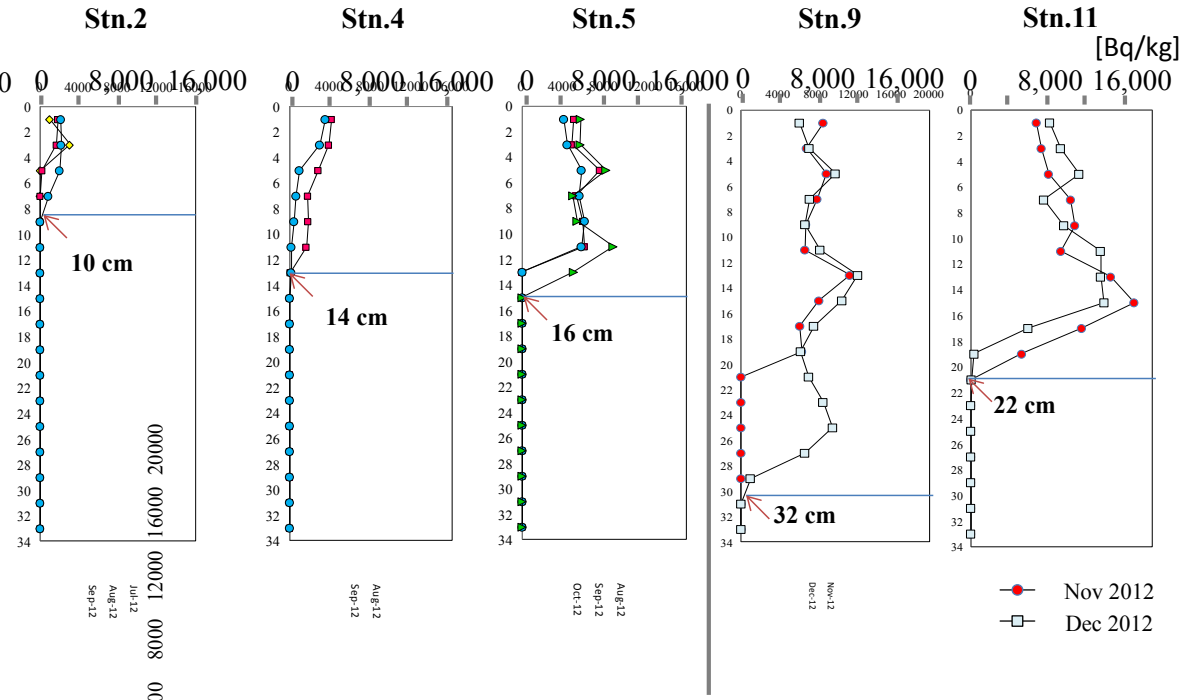

Fig. 4 - Time series of vertical profile of radiocesium concentration in Ohori River.

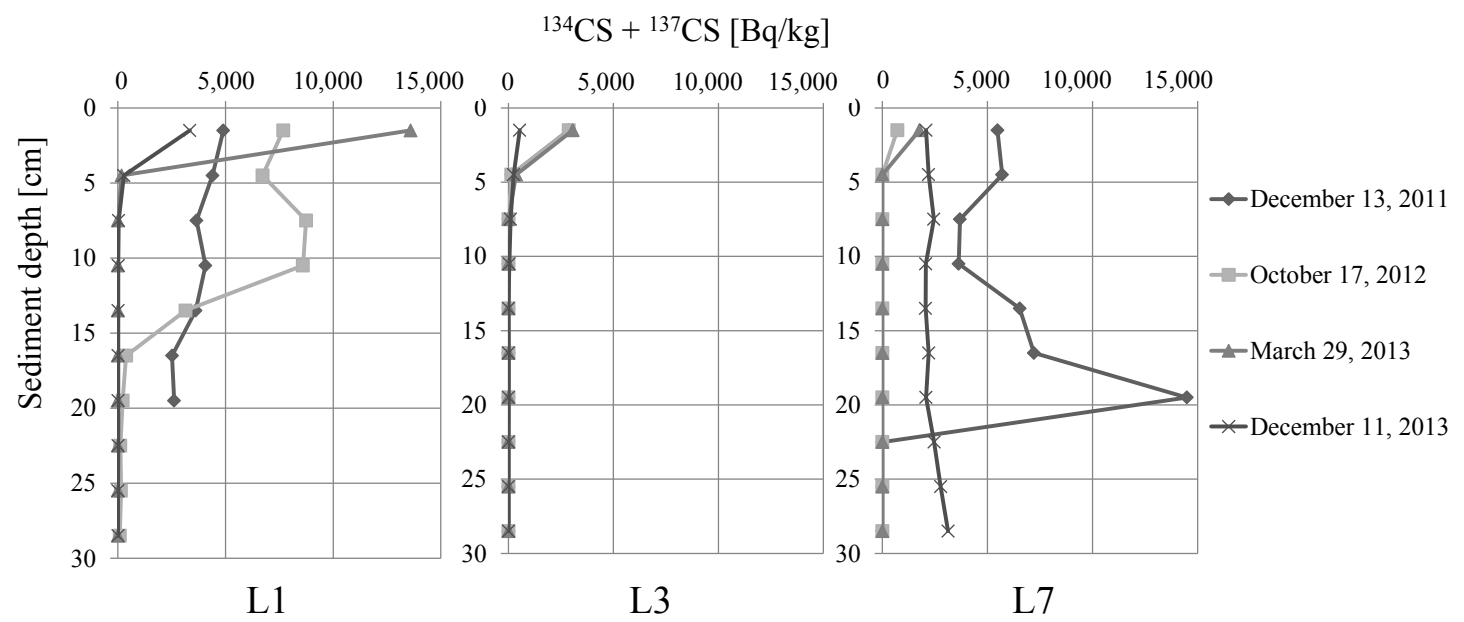

Fig. 5 - Time series of vertical profile of radiocesium concentration at three stations in Lake Teganuma. 


\section{Radiocesium flux due to fine-grained sediment transport}

Each flux and stock is summarized in Table 1. Radiocesium flux at Ohori River was $3,800 \mathrm{MBq} /$ year in 2012 and $6.7 \mathrm{MBq} /$ year in 2013, respectively, showing 3 orders of magnitude decrease. Since this decrease is larger than the decrease associated with a half-life, it is clear that the transport of fine-grained sediment is occurring rapidly. Also, since this observation started in October 2011, the conditions prior to that are unknown. However, it is assumed that the initial concentration was 3 orders of magnitude higher than in 2012. Generally, radiocesium in aquatic environments decreases exponentially (Smith et al., 2005). Thus, there must have been a large volume of transport occurring at the time of the accident in 2011. Also, this transport was high during Baiu (rainy season during June to early July) and typhoon season (during August to September), thus indicating that a large amount of precipitation enhances the transport of fine-grained sediment containing cesium.

To investigate the effects of sediment particle size on the concentration of radiocesium, sediments sampled at Stn.1 in Ohori River were sorted through sieving, and the concentration of radiocesium was measured. Table 2 shows radiocesium concentrations in different particle size. The concentrations of radiocesium attached to silt were significantly higher than other larger particles since finer particle has larger surface area for the radiocesium (He and Walling, 1996). More detailed sedimentation classification was not possible because we could neither separate particles smaller than $40 \mu \mathrm{m}$ by the method of sieves nor obtain a quantifiable amount of sample for the germanium semiconductor detector. If detailed classification were available, we could certainly verify that the concentration increases as the particle size decreases. At least, the above results suggest that a large amount of radiocesium attach to fine sediments such as silt and flow downstream together with the host. It is considered that the downstream flow of radiocesium, bonded on the surface of the mobile silt, explains the short-term radiocesium concentration variation in Ohori River as discussed earlier.

Table 1 - Summary of fluxes and stocks of radiocesium in Ohori River and Lake Teganuma on 2012 and 2013.

\begin{tabular}{lrrrr} 
Monitoring Area & $\mathbf{2 0 1 2}$ & $\mathbf{2 0 1 3}$ & Unit & \\
\hline \hline Watershed & & & & \\
Radiocesium stock in Ohori River watershed & $1,900,000$ & $1,500,000$ & $\mathrm{MBq}$ & June 2012/2013 \\
\hline Ohori River & & & & \\
Radiocesium flux & 3,800 & 6.65 & $\mathrm{MBq} /$ year & Yearly Average \\
Radiocesium stock in riverbed & 2,190 & 1,830 & $\mathrm{MBq}$ & 4 times average \\
Radiocesium polluted sediment stock in riverbed & 3,340 & 3,520 & ton & 4 times average \\
\hline Lake Teganuma & & & & \\
Radiocesium stock in lakebed & 740,000 & 610,000 & $\mathrm{MBq}$ & 3 times average \\
\hline \hline
\end{tabular}

Table 2 - Sediment classification and Cesium concentration.

\begin{tabular}{llll} 
Classification & $\mu \mathrm{m}$ & ${ }^{137} \mathrm{Cs}(\mathrm{Bq} / \mathrm{kg})$ & ${ }^{134} \mathrm{Cs}(\mathrm{Bq} / \mathrm{kg})$ \\
\hline \hline Fine sand & $106-250$ & 4690 & 1870 \\
\hline Very fine sand & $75-106$ & 5810 & 1910 \\
\hline Coarse Silt & $40-75$ & 7730 & 4020 \\
\hline Medium Silt & $<40$ & 23200 & 10030 \\
\hline
\end{tabular}


Radiocesium deposited on the riverbed at the same time of the year was $2,190 \mathrm{MBq}$ in 2012 and 1,830 MBq in 2013, respectively. Also, sediment weight was 3,300 ton in 2012 and 3,500 ton in 2013, respectively. This decrease in the radiocesium concentration originates in the decrease of cesium associated with half-life, and slight increase in the sediment weight is from fresh accumulation of sediment with a minute cesium contamination. The river channel of Ohori River is narrow, and the change in the flow volume is drastic. Thus, fine-grained sediment was mostly deposited at the mouth of the river.

The radiocesium deposited at the floor of Lake Teganuma was 740,000 MBq in 2012 and $610,000 \mathrm{MBq}$ in 2013, respectively. Similarly, the sediment weight showed a decrease from 2012 (440 kiloton) to 2013 (352 kiloton). This decrease in the radiocesium concentration was larger than the decrease of cesium associated with half-life Therefore, it indicates that the sediment contaminated with radiocesium is flowing out from Lake Teganuma to Tone River.

\section{Discussion}

The total amount of radiocesium that fell in the Ohori River basin was calculated to be $1.9 \mathrm{TBq}$ based on the airborne monitoring results (MEXT, 2011b). This is 3 orders of magnitude larger than the flux of cesium flowing down Ohori River in 2012. It is also an order of magnitude larger than radiocesium deposited in Ohori River and Lake Teganuma. Since the observation in 2011 started in October, the year 2011 was excluded from the flux calculation. But based on the above-listed fluxes and stocks, a significant transport of radiocesium in Teganuma basin occurred in 2011, and much of it was already deposited at the base of Ohori River and Lake Teganuma by the time the observation started in October 2011. This amounts to $10 \%$ of radiocesium that fell in the basin, and the remaining $90 \%$ must have stayed in the basin.

Meanwhile, Nihei et al. (2013) estimated the existing amount of radiocesium in the Lake Teganuma at the end of July 2012 to be $0.81 \mathrm{TBq}$, roughly $10 \%$ greater than the yearly average in 2012 found in this study $(0.74 \mathrm{TBq})$. The difference is minor, considering that the times are different and that the radiocesium concentration decreases with time. Moreover, Nihei et al. (2013) estimated the total inflow flux from the watershed area to be $0.81 \mathrm{TBq}$ based on the existing amount of radiocesium in the Lake Teganuma and $0.091-0.186 \mathrm{TBq}$ obtained by multiplying the amount of sediment 2,600 ton from the watershed area of the Lake Teganuma and the radiocesium concentration in the area $(0.81 \mathrm{TBq})$. The estimated values vary more than 10 times; to minimize the difference between the estimated values, they proposed to use 310,000 $\mathrm{Bq} / \mathrm{kg}$ as the radiocesium concentration in the area.

In estimating the inflow flux from the existing amount in the Lake Teganuma, they assumed that the radiocesium accumulated in the Lake Teganuma after 2011 was all kept in the Lake without outflow. However, a large error could result from the assumption because fine sediments, such as silt, flow out of the Lake as our observation suggested. The calculation in our study gives the flux in Ohori River, instead of the total inflow flux from the Lake Teganuma watershed area, and the values cannot be directly compared. In addition, Nihei et al. (2013) assumed a constant radiocesium concentration in suspended sediment while this study uses monthly measured values. 
However, the flux in Ohori River calculated in this study is 3,800 MBq/year in 2012 and $6.65 \mathrm{MBq} /$ year in 2013, which is very small compared with the amount accumulated in the Lake; this agrees with what Nihei et al. (2013) asserted. This tendency is reasonable, assuming that the amount in 2011 was several orders of magnitude greater than in 2012 as evidenced by the fact that the transportation of radiocesium in Ohori River occurred in a short term and that the flux of radiocesium decreased three orders of magnitude in a year, from 2012 to 2013. In other words, it is reasonable that the flux is small in 2012 and 2013 compared with the total amount of deposited sediment if we assume that the transported amount in 2011 was several orders of magnitude greater than in 2012. In addition, the flux in 2011 was large not due to a large amount of sediment transportation but very possibly because of a high radiocesium concentration; this practically agrees with the proposal of Nihei et al. (2013) assuming a high radiocesium concentration in the watershed area.

When a similar study was conducted on Abukuma River, only $1 \%$ of the total fallout was calculated as a flux in the aquatic system. Sixty per cent of the fallout is considered to have been transported during the typhoon in August 2011 (Yamashiki et al., 2014). In the Abukuma River's research, only the flux was shown. The Flux and deposited amount are different and cannot be easily compared. However, the results of this study showed that as of 2012, radiocesium deposited on the riverbed and lake bottom is about $10 \%$ of the total fallout, indicating that the transport 10 times that of Abukuma River occurred in this basin. Also, the reason for this is believed to be urbanization of Teganuma basin compared to Abukuma basin, thus more radiocesium was transported in a shorter time period compared to a wooded area.

Also, radiocesium in Lake Teganuma showed a notable transport after 2013. Since Lake Teganuma is shallow (average depth of $0.9 \mathrm{~m}$ ), the bottom sediment is churned during strong winds, enhancing the transport. Because of that, it is possible that similar to Ohori River, a significant amount of transport already occurred during Baiu and typhoons of 2011, leading to the flow of radiocesium into Tone River. A high concentration of radiocesium was observed at the outlet of Lake Teganuma (Stn.L7) at the time of initial observation in October 2011. If it is considered that this is the result of typhoon that occurred in August, radiocesium flows from Baiu in June 2011 were already flowed out to Tone River by the time the observation started in October 2011.

In this research, the period over which radiocesium transport is calculated was set to be after October 2011 when the observation was started. It is possible to estimate from March 2011 using extrapolation, but the focus was put on the information obtainable from observation results. If detailed quantification becomes possible from atmospheric/weather models, this issue will be reconsidered. Our study also ignores the bed load, thus cannot consider the vertical distribution of suspended sediment particle in water, because Ohori River is shallow. Observations were made every few months, therefore small precipitation events and flux variation were not discussed.

\section{CONCLUSIONS}

The radiocesium flux was calculated from observation results in Ohori River basin where urbanization is progressing. It became clear that 10 times fluxes of Abukuma 
basin has occurred in a much shorter time frame. This is because in urban areas surrounded by asphalt and buildings with highly developed sewer systems will less accumulate radiocesium, but instead it is transported in a short time frame through artificial waterways. Therefore, in urban areas, even if the fallout amount of radiocesium was small, the proportion of fluxes in aquatic system is high, concentrating the radiocesium at areas such as river mouth in a short time frame.

Also, this study showed that radiocesium that was easily transported had already migrated to Lake Teganuma, and some of it had already flowed out to Tone River. In addition, fine-grained sediment accumulating in rivers showed a change to lower concentration of radiocesium. From that, it is considered unlikely that the concentration of radiocesium would increase in this basin.

\section{ACKNOWLEDGEMENTS}

This research was supported by Grant-in-Aid for Scientific Research on Innovative Areas Grant Number 24110004 and Core Research for Evolutional Science and Technology (CREST) Program "A tracer simulator of fallout radionuclides for safe and sustainable water use" of Japan Science and Technology Agency (JST).

\section{REFERENCES}

Chino M., Nakayama H., Nagai H., Terada H., Katata G. and Yamazawa H. (2011) Preliminary estimation of release amounts of ${ }^{131} \mathrm{I}$ and ${ }^{137} \mathrm{Cs}$ accidentally discharged from the Fukushima Daiichi Nuclear Power Plant into the atmosphere. J. Nucl. Sci. Technol., 48(7), 1129-1134.

Division of Agriculture, Forestry and Fisheries of Chiba Prefecture (2012) Suisanbutsu Housyanou Sokutei Kekka (Radiation monitoring results of aquatic products). Division of Agriculture, Forestry and Fisheries of Chiba Prefecture, Japan. http://www.pref.chiba.lg.jp/gyoshigen/housyanou/jisyukuyousei/teganuma-motugof una.html (accessed April. 29, 2015). (in Japanese)

Golosov V. N., Belyaev V. R. and Markelov M. V. (2012) Application of Chernobylderived ${ }^{137} \mathrm{Cs}$ fallout for sediment redistribution studies: lessons from European Russia. Hydrol. Processes, 27, 781-794.

He Q. and Walling D. E. (1996) Interpreting particle size effects in the adsorption of ${ }^{137} \mathrm{Cs}$ and unsupported ${ }^{210} \mathrm{~Pb}$ by mineral soils and sediments. J. Environ. Radioact., 30(2), 117-137.

Hirose K. (2012) Fukushima Dai-ichi nuclear power plant accident: summary of regional radioactive deposition monitoring results. J. Environ. Radioact., 111, 13-17.

IAEA (2006) Radioactivity in the Dnieper River Basin. Radiological conditions in the Dnieper River Basin, assessment by an international expert team and recommendations for an action plan. Radiological Assessment Reports Series, International Atomic Energy Agency, Vienna, pp.15-20.

JAEA (2011) A trial calculation on total amount of radiation exposure during 2 months after the accident of Fukushima Daiichi Nuclear Power Plant in TEPCO. Japan Atomic Energy Agency, Tokai, Japan. http://www.jaea.go.jp/jishin/kaisetsu03/kaisetsu03.htm (accessed Sep. 12, 2014). (in Japanese) 
JMA (2014) AMeDAS hourly observation results. Japan Meteorological Agency, Tokyo, Japan. http://www.jma.go.jp/jp/amedas_h/today-45061.html (accessed Sep. 12, 2014). (in Japanese)

Kato H., Onda Y. and Gomi T. (2012) Interception of the Fukushima reactor accidentderived ${ }^{134} \mathrm{Cs},{ }^{137} \mathrm{Cs}$ and ${ }^{131} \mathrm{I}$ by coniferous forest canopies. Geophys. Res. Lett., 39, L20403.

Kimura M. and Koibuchi Y. (2010) Field observation of chlorophyll and dissolved oxygen in Lake Teganuma. J. JSCE Ser. B1 (Hydraul. Eng.), 66(4), 1117-1122. (in Japanese)

MEXT (2011a) Readings of environmental radiation level of dust and soil by monitoring in schools in Fukushima Prefecture. Ministry of Education Culture Sports Science and Technology, Tokyo, Japan. http://www.mext.go.jp/english/incident/1305657.htm (accessed Sep. 12, 2014).

MEXT (2011b) Results of airborne monitoring survey by MEXT in Saitama and Chiba prefectures. Ministry of Education Culture Sports Science and Technology, Tokyo, Japan. (in Japanese)

MLIT (2014) Water level observation results. Ministry of Land, Infrastructure, Transport and Tourism, Japan. http://www.river.go.jp/nrpc0305gDisp.do?mode=\&officeCode=21269\&obsrvtnPoint Code $=24 \&$ timeAxis $=60$ (accessed Sep. 12, 2014). (in Japanese)

Morino Y., Ohara T. and Nishizawa M. (2011) Atmospheric behavior, deposition, and budget of radioactive materials from the Fukushima Daiichi Nuclear Power Plant in March 2011. Geophys. Res. Lett., 38, L00G11.

Nagao S., Kanamori M., Ochiai S., Tomihara S., Fukushi K. and Yamamoto M. (2013) Export of ${ }^{134} \mathrm{Cs}$ and ${ }^{137} \mathrm{Cs}$ in the Fukushima river systems at heavy rains by Typhoon Roke in September 2011. Biogeosci. Discuss., 10, 2767-2790.

Nihei Y., Oouchida T., Sasagawa K., Hashida H. and Takekawa K. (2013) Study on movement of radioactive cesium-134 and -137 in urban watershed, river and lake: an example of watershed of the Lake Teganuma. J. JSCE Ser. B1 (Hydraul. Eng.), 69(4), I1693-I1698. (in Japanese)

Reid I. and Laronne J. B. (1995) Bed load sediment transport in an ephemeral stream and a comparison with seasonal and perennial counterparts. Water Resour. Res., 31(3), 773-781.

Smith J. and Nicholas A. B. (2005) Chernobyl: catastrophe and consequences. Springer-Praxis Books in Environmental Sciences, Springer, Heidelberg, Germany.

Smith J. T., Belova N. V., Bulgakov A. A., Comans R. N. J., Konoplev A. V., Kudelsky A. V., Madruga M., Voitsekhovitch O. V. and Zibold G. (2005) The "aquascope" simplified model for predicting Sr-89, Sr-90, I-131, and Cs-134, Cs-137 in surface waters after a large-scale radioactive fallout. Health Phys., 89(6), 628-644.

Yamashiki Y., Onda Y., Smith G. H., Blake H. W., Wakahara T., Igarashi Y., Matsuura Y. and Yoshimura K. (2014) Initial flux of sediment-associated radiocesium to the ocean from the largest river impacted by Fukushima Daiichi Nuclear Power Plant. Sci. Rep., 4, 3714, doi:10.1038/srep03714.

Yasunari T. J., Stohl A., Hayano R. S., Burkhart J. F., Eckhardt S. and Yasunari T. (2011) Cesium-137 deposition and contamination of Japanese soils due to the Fukushima nuclear accident. PNAS, 108(49), 19530-19534. 